\title{
The Evaluation of a Moodle Based Adaptive e-Learning System
}

\author{
Herman Dwi Surjono
}

\begin{abstract}
This paper discusses the evaluation of an adaptive e-learning system based on student's learning styles that has been developed using LMS Moodle. Two popular models of learning styles used are VAK and Felder. The VAK learning styles include visual, auditory, and kinesthetic, whereas the Felder learning styles include global and sequential. The evaluation focuses on the alpha and beta testing. The result shows that the adaptive e-learning system and all adaptation functionalities have performed correctly.
\end{abstract}

Index Terms-Adaptive, e-learning, learning styles, moodle.

\section{INTRODUCTION}

The World Wide Web has become an increasingly powerful, global and interactive medium for sharing information. The advances of web technologies have boosted development of new learning experiences for students. One of the first types of web application for delivering instruction via the Internet is web-based instruction that is now known as e-learning. E-learning is a hypermedia-based instructional program that utilizes the attributes and resources of the Web to create a meaningful learning environment [1]. E-learning is just the integration of the traditional Computer Assisted Instruction (CAI) or Computer Based Training (CBT) into web technology. Since then e-learning has been a hot research and development area. Benefits of e-learning are both classroom and platform independence.

There are many e-learning systems available on the Internet, but they provide only the same plain hypertext pages to all students regardless of individual ability. In many current web-based courses, the course material is still implicitly oriented for a traditional on-campus audience consisting of homogeneous, well-prepared and wellmotivated students. However, web-based courses are used by a much wider variety of users than any campus-based courses. These learners may have very different goals, backgrounds, knowledge levels and learning capabilities. A web-based course designed for a specific group of users, like a traditional course, may not fit other users. Therefore the course material needs to be flexible so that different students may get different materials and an order of presentation that depends upon their own characteristics.

Adaptive e-learning systems (AES) try to solve these problems by altering the presentation of material to suit

Manuscript received July 11, 2013; revised September 12, 2013.

Herman Dwi Surjono is with Electronics Education Department, Engineering College, Yogyakarta State University, Yogyakarta, Indonesia (e-mail: hermansurjono@uny.ac.id). each individual student [2]. AES combine ideas from hypermedia systems and intelligent tutoring systems to adapt the systems to the particular user. They use a model of the user to collect information about his or her goals, preferences and knowledge, and use this model throughout the interaction with the user in order to adapt to the needs of that user [3].

This paper discusses the evaluation of an adaptive elearning system based on student's learning styles that is developed using LMS Moodle. Two popular learning styles will be explored and used as basis for implementing the adaptation mechanism. The evaluation itself is focussing on the alpha and beta testing when the development has finished.

\section{ADAPTIVE E-LEARNING SYSTEM}

Adaptive e-learning system (AES) is a recently established area of research integrating technologies of CAI, ITS and hypermedia systems [4]. There are at least two reasons driving the advances of AES. First, AES are typically used by much more heterogeneous users than any standalone computer-based learning application. Any webbased learning system that is designed for a specific group of users may not suit other users. Second, generally the user of AES is working without any assistance from teachers, as would be the case in a traditional classroom situation.

The basic components of AES are the domain model, the student model and the adaptation model [5]. The domain model is the area or topic for which AES is intended as a resource. The student model is a collection of characteristics for which specific values are recorded for each user. The adaptation model is essentially a definition of what parts of the e-learning can be adapted and under what circumstances this adaptation is to occur [6].

The main factor to provide adaptivity in the AES is the student model that represents relevant aspects of the student such as preferences, knowledge and interests [7]. The student model dynamically maintains information for each user such as his/her knowledge, preferences, etc. The system collects this student information by observing the use of the application, by presenting series of questionnaires or feedback forms. The more accurate the student model is, the more advanced the adaptation that can be provided.

According to Huitt [8], the learning process is complex and may be influenced by many factors including student characteristics. There are many student characteristics that are related to the learning process; among others, these are prior knowledge, intelligence, study habits, age, gender, motivation, learning style, cognitive development, socioemotional development, moral and character development. 
The student model should therefore accommodate these factors as much as possible in order for the adaptive elearning to adapt accurately to the student's needs.

There are two types of adaptation in the AES depending on who takes the initiatives: the system or the student [9]. If the system which initiates, it is called adaptivity and if the student who initiates, it is called adaptability. Adaptivity means the capability of a system to adjust its presentation according to the student characteristics automatically, whereas adaptability means the capability of the system to support user adjustment.

The term adaptive is often confused with adaptable. Systems that adapt to the users automatically based on the system's assumptions about user needs are called adaptive. Systems that allow the user to change certain system parameters and adapt their behaviour accordingly are called adaptable [10]. An important characteristic of adaptive systems, identified by Jameson [11], is that the systems adapt their behaviour to each individual user on the basis of non-trivial inferences from information about that user. The adaptivity is limited by non-trivial inferences to exclude straightforward trivial adaptations that are usually adopted by all kinds of systems.

The systems that have only these trivial adaptations are called adaptable and not adaptive. Adaptable systems are not based on intelligent algorithms that infer how to adapt on their own. They just offer a flexibility to change the interface or the behaviour manually according to user needs or preferences. According to Cristea and De Bra [12], the lowest level of intelligence for web-based instruction is to have some adaptable features, i.e. the user has some options that will determine some alterations to the aspect, contents or functionality of the web material. These static adaptable features are classified as adaptability.

On the other hand, compared to adaptability, adaptivity represents a more advanced step towards artificial intelligence. The actual capability of adaptive systems is to adapt automatically to the new conditions that are usually deduced from the user model [12]. In developing an adaptive e-learning system, it is important to balance between these two levels of adaptation [13].

\section{LEARNING STYLES}

The choice of learning style as one of the student characteristics processed by the student model is based on the following research studies. According to Rasmussen [14], when a student's individual learning style is taken into account in the learning process, the student's achievement is improved. Other researches on learning style have indicated that different students learn differently: some students learn more effectively when taught with their preferred method, and students' achievements are related to how students learn [15]. Learning style influences the effectiveness of training, whether that training is provided on-line or in more traditional ways [16]. These studies indicate the importance of learning styles in the learning process.

There are various models of learning styles from the literature. Two popular models used in this AES are VAK and Felder. The VAK learning styles include visual, auditory, and kinesthetic, whereas the Felder learning styles include global and sequential. According to Sarasin [17], the VAK learning styles refer to human observation channels: vision, hearing and feeling. It suggests that learners can be divided into one of three preferred learning styles, i.e. Visual, Auditory or Kinesthetic. Visual learners can learn effectively when they see the materials; Auditory learners like to hear the material, whereas Kinesthetic learners are those who learn best by doing. These three classifications are known as VAK learning styles.

Learning styles are often measured using a questionnaire or psychometric test. The questionnaire comprises several questions about learner personality, attitude, and behaviour. In this $\mathrm{AES}$, the questionnaire includes indicators to measure the learner preferred learning styles of Visual, Auditory or Kinesthetic and Global or Sequential. Based on the scores the learners obtain, they can be classified into one of these categories (known as learning modes):

- Global-Visual

- Global-Auditory

- Global-Kinesthetic

- Sequential-Visual

- Sequential-Auditory

- Sequential-Kinesthetic

In this AES, it is used a learning mode term which refers to a combination of presentation mode Global-Sequential with variations of VAK. Because there are six types of learning modes that must be accommodated, then the system must provide six kinds of presentations. Learning mode of "Global-Visual" means the material is presented globally by focusing on the visual aspect. Learning mode of "Global-Auditory" means the material is presented globally with major elements of the audio aspect. Learning mode of "Global-Kinesthetic" means the material is presented globally with emphasis on the Kinesthetic aspect. For the other three learning modes that are "Sequential-Visual", "Sequential-Auditory", "Sequential-Kinesthetic", the learning materials are the same as the three previous modes, but they are presented sequentially.

\section{MoOdle BASEd AES DEVElopMEnT}

The development of the AES is different in some respects form other software development in general. According to Koch [18], this difference is mainly concerned with navigational facilities, the role of the user, and dynamic adaptation of learning materials and presentations as well as navigation. The model development is done through an engineering approach as follows.

The analysis is the first step in the development of AES model. In this step, it is generated a description of system requirements, a description of system functions and the main features of the system which is expected. This AES is expected to provide a presentation of learning materials which vary according to the tendency of the user's learning style. Thus the system must be able to identify the diversity of learning styles of users and take advantage of user data as considerations to deliver presentations

An adaptivity mechanism that is used to decide whether a student will get a certain learning mode is very simple. As it was described in the system design [19], students have to fill out the questionnaires when the first time accessing the 
adaptive course. The questionnaire contains questions that ask the tendency of learning styles in which the answers are grouped into two, the first group: visual, auditory, kinesthetic and second group: global, sequential. For example if a student obtains the highest score on the visual aspect of the first group and highest score on the global aspect of the second group, then students will continue with the learning mode of "Global-Visual". Another example, a student will continue with a learning mode of "SequentialAuditory", if she or he gets the highest score on the auditory aspect of the first group and highest score on the sequential aspect of the second group.

The next step was design that produces a system architecture based on a summary of the functional systems and features of adaptive e-learning systems. The implementation is next step that would be the realization of the system design through a programming work. A Learning Management System of Moodle was chosen as a platform for the implemetation. In order to customize the list of questions within the questionnaire, teachers are allowed to edit the questionnaires. Fig. 1 shows a list of questions edited by teacher.

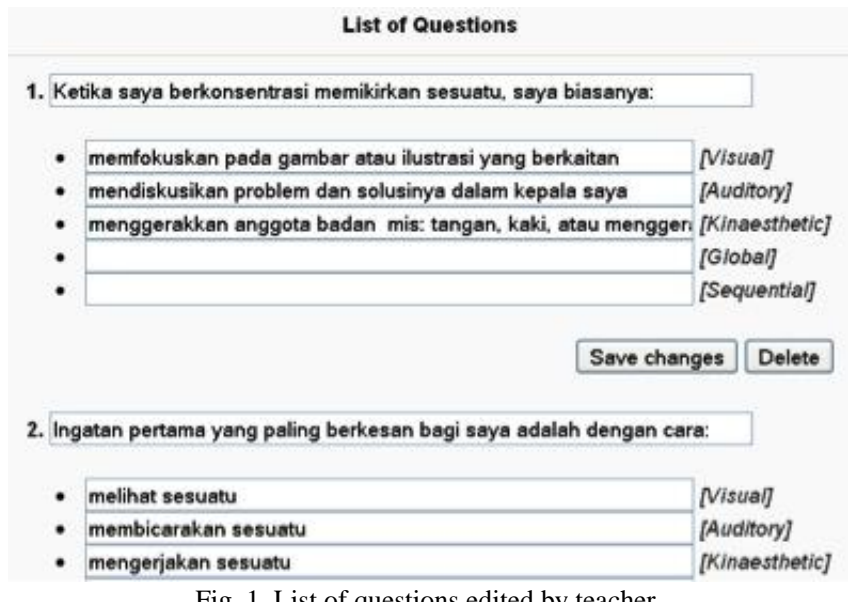

Fig. 1. List of questions edited by teacher.

The number of questions in the questionnaires must be odd or cannot be divided by 3 for the first group and cannot be divided by 2 for the second group. The disadvantage of this mechanism, among others, although the number of questions is not divisible by 3 , but there is still a possibility that the two aspects got the same score. If this happens, then the system will choose the one that may not match the student's learning styles. In addition, when filling out the questionnaire for the second chance, students may still remember some of the questions, if this happens then the score may not reflect their actual learning styles.

As a standard Moodle does not consider individual differences of learners and treat all learners equally, in order to accommodate the learners' learning styles of Visual, Auditory or Kinesthetic and of Global or Sequential; it needs to be customized. Customizing Moodle to implement the system design includes creating some modules, blocks, and course format within the Moodle. In order to serve the adaptivity mechanism, it has been created within the Moodle three modules of assignment, quiz and resource, four blocks of adaptive and one course format.

Teachers are responsible for devising and editing all the learning materials. When teachers want to make one topic of learning materials, they have to make the topic for all six types of learning mode accordingly. There is one additional section categorized as common that can be seen by all students. The common section may contain information such as course schedule, syllabus, discussion forum, etc. Fig. 2 shows a teacher's view when they are editing a course page.

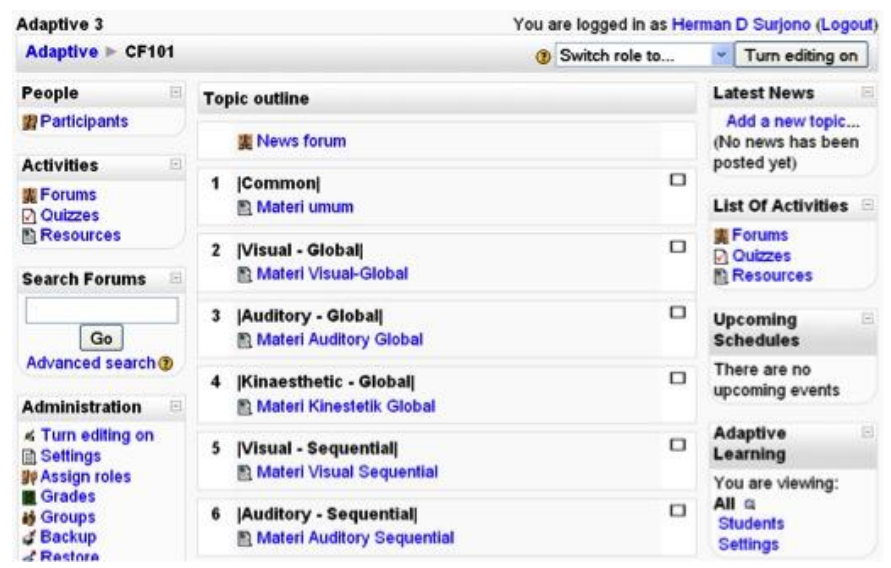

Fig. 2. Teacher's view of a course page.

When a student that has a certain learning style see the course page, all the materials will not be presented, but only one material will show. Fig. 3 shows a student's view when he/she has a learning mode of auditory-global.

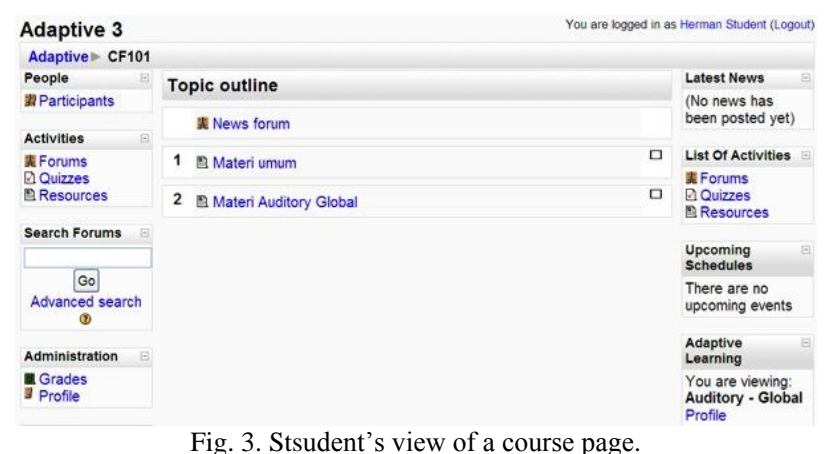

\section{AES Evaluation}

The overall evaluation for the developed AES can be divided into two, namely formative evaluation and summative evaluation. The formative evaluation is carried out when the development process is still ongoing with the aim that a better system can be achieved before the system is widely used by the user. The summative evaluation is conducted when the system is done and is widely used by users in order to determine the effectiveness of AES in the learning activities.

This paper only presents the formative evaluation that includes ongoing, alpa and beta testing. The results of this evaluation can be described as follows. The ongoing evaluation was conducted by researchers at every stage of the system development, i.e. ranging from analysis, design to implementation. The ongoing evaluation at the design and implementation stage was done by way of comparing whether the work was done in line with the functional system. In the event of non-compliance, then the job was immediately corrected. With this ongoing evaluation, the final result would meet the expected criteria.

The final performance of the adaptive e-learning was obtained through alpha and beta testing by observing if the 
system is working in accordance with the expected adaptivity functionality. The summay of the evaluation results can be seen at Table I.

\begin{tabular}{|c|c|c|c|}
\hline No & Adaptivity Functionality & Yes & No \\
\hline 1. & Teacher can set a course format to adaptive & $\checkmark$ & \\
\hline 2. & $\begin{array}{l}\text { Teacher can compose questionnaire and its } \\
\text { setting }\end{array}$ & $\sqrt{ }$ & \\
\hline 3. & $\begin{array}{l}\text { Student obtains questionnaire scores and is } \\
\text { assigned to particular learning mode }\end{array}$ & $\checkmark$ & \\
\hline 4. & $\begin{array}{l}\text { Student can see his/her learning mode } \\
\text { history }\end{array}$ & $\sqrt{ }$ & \\
\hline 5. & $\begin{array}{l}\text { Teacher can author six different learning } \\
\text { materials in accordance with their respective } \\
\text { learning modes }\end{array}$ & $\sqrt{ }$ & \\
\hline 6. & $\begin{array}{l}\text { Student can only see the learning materials } \\
\text { in accordance with his/her learning styles }\end{array}$ & $\sqrt{ }$ & \\
\hline 7. & $\begin{array}{l}\text { Teacher can make six different assignments } \\
\text { and quizzes in accordance with their } \\
\text { respective learning modes }\end{array}$ & $\checkmark$ & \\
\hline 8. & $\begin{array}{l}\text { Student can only see the assignments and } \\
\text { quizzes in accordance with his/her learning } \\
\text { mode }\end{array}$ & $\checkmark$ & \\
\hline 9. & $\begin{array}{l}\text { Teacher can change the setting of student's } \\
\text { learning mode }\end{array}$ & $\checkmark$ & \\
\hline 10. & $\begin{array}{l}\text { Teacher can change the setting of learning } \\
\text { materials, assigments, quizzes to any other } \\
\text { learning mode }\end{array}$ & $\sqrt{ }$ & \\
\hline 11. & $\begin{array}{l}\text { Student can see recent activities and up } \\
\text { coming caledar in accordance with his/her } \\
\text { learning styles }\end{array}$ & $\checkmark$ & \\
\hline
\end{tabular}

\section{CONCLUSIONS}

The AES that is evaluated in this paper presents learning materials that match students' learning styles i.e. visual, auditory and kinesthetic either globally or sequentially. The system identifies the student's learning styles tendency through a set of questionnaire. The questionnaire scores are used by the system as basis to provide the student a presentation of learning materials differently.

The system is implemented by customizing the LMS of Moodle. The ongoing evaluation at the design and implementation stage is done to make sure that every feature of the system works well. The evaluation results show that all adaptation functionalities of the adaptive elearning has performed correctly.

\section{REFERENCES}

[1] B. H. Khan, "Web-based instruction (WBI): What is it and why is it?" In Web-based instruction, B. H. Khan, Ed. Englewood Cliffs, NJ: Educational Technology Publications, 1997, pp. 5-18.

[2] P. Brusilovsky, "Methods and techniques of adaptive hypermedia," User Modeling and User Adapted Interaction, vol. 6, no. 2-3, pp. 87129, 1996.

[3] P. Brusilovsky, "Adaptive hypermedia," User Modeling and User Adapted Interaction, vol. 11, pp. 87-110, 2001.

[4] D. P. da Silva, R. V. Durm, E. Duval, and H. Olivié, "Concepts and documents for adaptive educational hypermedia: A model and a prototype," presented at the 2nd Workshop on Adaptive Hypertext and Hypermedia HYPERTEXT"98, Pittsburgh, June 20-24, 1998.
[5] M. Cannataro, A. Cuzzocrea, C. Mastroianni, R. Ortale, and A. Pugliese, "Modeling adaptive hypermedia with an object-oriented approach and XML," presented at the 2nd International Workshop on Web Dynamics (WebDyn 2002) in conjunction with the 11th International World Wide Web Conference (WWW 2002), Honolulu, Hawaii, 2002.

[6] R. Pascoe and A. Sallis, "A pedagogical basis for adaptive WWW textbooks," presented at the North American Web Developers Conference, Fredericton, NB, Canada, October, 1998.

[7] P. Brusilovsky, S. Ritter, and E. Schwarz, "Distributed intelligent tutoring on the web," presented at the 8th World Conference on Artificial Intelligence in Education, Kobe, Japan, August 18-22, 1997.

[8] W. Huitt, "A transactional model of the teaching/learning process," in Educational Psychology Interactive, Valdosta, GA: Valdosta State University, 2003.

[9] J. Kay, "Learner control," User Modeling and User Adapted Interaction, vol. 11, no. 1-2, pp. 111-127, 2001.

[10] R. Oppermann, R. Rashev, and Kinshuk, "Adaptability and adaptivity in learning system," presented at the Knowledge Transfer, London, UK, July 14-16, 1997.

[11] A. Jameson, "User-adaptive and other smart adaptive systems: Possible synergies," presented at the Proceedings of the first EUNITE Symposium, Tenerife, Spain. 2001.

[12] A. Cristea, and P. De Bra, "ODL education environments based on adaptivity and adaptability," presented at the World Conference on ELearning in Corp., Govt., Health, \& Higher Ed., ELEARN, 2002.

[13] Papanikolaou, M. Grigoriadou, H. Kornilakis, and G. D. Magoulas, "Personalizing the interaction in a web-based educational hypermedia system: The case of INSPIRE," User Modeling and User Adapted Interaction, vol. 13, no. 3, pp. 213-267, 2003

[14] K. L. Rasmussen, "Hypermedia and learning styles: Can performance be influenced?" Journal of Multimedia and Hypermedia, vol. 7, no. 4, 1998.

[15] R. Riding and S. Rayner, Cognitive styles and learning strategies, London: David Fulton Publisher, 1998.

[16] H. C. Benham, "Training effectiveness, online delivery and the influence of learning style," presented at the 2002 ACM SIGCPR Conference on Computing Personal Research, Kristiansand, Norway, 2002.

[17] L. C. Sarasin, Learning Style Perspectives, Impact in the Classroom, Madison, WI: Atwood Publishing, 1999.

[18] N. Koch, "Software engineering for adaptive hypermedia systems: Reference model, modeling techniques and development process," $\mathrm{Ph} . \mathrm{D}$. dissertation, Ludwig-Maximilians-Universität München, München, 2000.

[19] H. D. Surjono, "The design of adaptive e-Learning system based on student's learning styles," International Journal of Computer Science and Information Technology (IJCSIT), vol. 2, no. 5, pp. 2350-2353, 2011.

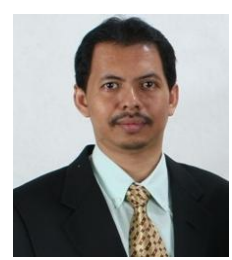

Herman Dwi Surjono is a lecturer at the College of Engineering and the Graduate School of the Yogyakarta State University, Indonesia. He got his master degree from the Iowa State University in 1995. He received his Ph.D. in Information Technology in 2006 from Southern Cross University Australia.

$\mathrm{He}$ teaches both undergraduate and graduate students computer programming, e-learning, interactive multimedia, and digital media. His research area includes adaptive hypermedia, computer based learning, and e-learning. He has experiences in providing consulting and training and development of Moodle based e-learning. He has published articles and books related to e-learning and multimedia. His goal is to empower teachers to optimize the use of e-learning in schools. At the moment he is a head of Instructional Technology Department at the Graduate School of YSU. He is a Senior Member No: 80343064 International Association of Computer Science and Information Technology (IACSIT) since 2011. 